\title{
Three dimensional imaging of electrical trees in micro and nano-filled epoxy resin
}

DOI:

10.1109/CEIDP.2014.6995882

Link to publication record in Manchester Research Explorer

\section{Citation for published version (APA):}

Schurch, R., Rowland, S. M., Bradley, R. S., Hashimoto, T., Thompson, G. E., \& Withers, P. (2014). Three dimensional imaging of electrical trees in micro and nano-filled epoxy resin. In host publication IEEE. https://doi.org/10.1109/CEIDP.2014.6995882

\section{Published in:}

host publication

\section{Citing this paper}

Please note that where the full-text provided on Manchester Research Explorer is the Author Accepted Manuscript or Proof version this may differ from the final Published version. If citing, it is advised that you check and use the publisher's definitive version.

\section{General rights}

Copyright and moral rights for the publications made accessible in the Research Explorer are retained by the authors and/or other copyright owners and it is a condition of accessing publications that users recognise and abide by the legal requirements associated with these rights.

\section{Takedown policy}

If you believe that this document breaches copyright please refer to the University of Manchester's Takedown Procedures [http://man.ac.uk/04Y6Bo] or contact uml.scholarlycommunications@manchester.ac.uk providing relevant details, so we can investigate your claim.

\section{OPEN ACCESS}


This is the accepted manuscript, which has been accepted by IEEE for publication (C) 2014 IEEE. Personal use of this material is permitted. Permission from IEEE must be obtained for all other uses, in any current or future media, including reprinting/republishing this material for advertising or promotional purposes, creating new collective works, for resale or redistribution to servers or lists, or reuse of any copyrighted component of this work in other works. The full reference is:

'Three dimensional imaging of electrical trees in micro and nano-filled epoxy resin'

R. Schurch, S. M. Rowland, R. S. Bradley, T. Hashimoto, G. E. Thompson and P. J. Withers

IEEE Conference on Electrical Insulation and Dielectric Phenomena, Des Moines, pp. 39-42 (2014)

DOI: $\underline{\text { 10.1109/CEIDP.2014.6995882 }}$ 


\section{Three dimensional imaging of electrical trees in micro and nano-filled epoxy resin}

\author{
Roger Schurch ${ }^{1}$ and Simon M. Rowland \\ School of Electrical and Electronic Engineering \\ The University of Manchester \\ Manchester, United Kingdom \\ s.rowland@manchester.ac.uk
}

\author{
Robert S. Bradley, Teruo Hashimoto, \\ George E. Thompson and Philip J. Withers \\ School of Materials \\ The University of Manchester \\ Manchester, United Kingdom
}

\begin{abstract}
The authors have previously shown that electrical trees in unfilled polymers can be three-dimensionally (3D) imaged using X-ray computed tomography (XCT) or serial blockface scanning electron microscopy (SBFSEM). Here, we present the results of 3D imaging and analysis of electrical trees in filled epoxy systems for the first time. Electrical trees created in unfilled, micro silica-filled and nano silica-filled epoxy resin were scanned using XCT at the Diamond Light Source synchrotron and then also imaged using SBFSEM. 3D virtual replicas of the trees have been generated and their structures characterised. Imaging in micro-filled epoxy is more challenging than in nanofilled epoxy. It was found that trees in samples filled up to $20 \mathrm{wt} \%$ with micro silica can be imaged using either XCT or SBFSEM. In the case considered, the mean diameter of tree channels in micro-filled epoxy was found to be considerably smaller $(0.6 \mu \mathrm{m})$ than in unfilled or nano-filled epoxies $(3 \mu \mathrm{m})$.
\end{abstract}

\section{INTRODUCTION}

The addition of inorganic fillers is a common practice for epoxy systems. Micro-fillers (mainly silica) have been widely used in the industry to improve thermal and mechanical properties of the material. Over the last decade, nanocomposites have received considerable attention [1], results suggesting that nano-fillers in particular improve PD resistance and treeing lifetime [2]. Normally, micro-fillers are added in large quantities to the compound, typically around 50 wt\% [1], while nano-fillers are optimally added in smaller amounts, typically a few wt $\%$. It has been suggested that micro fillers affect tree propagation, increasing the branching and contortion of tree segments as they encounter filler particles [3]. It has also been proposed that nano particles modify the nature of the host polymer offering a very large interfacial area and these act like barriers for tree propagation [4]. However, no clear evidence of these models has been provided and the interaction between filler/tree is not fully understood.

Imaging methods are a common tool for studying electrical treeing phenomena[5]. Electrical trees created in translucent materials are analysed using conventional optical methods. However, translucent epoxy turns opaque when is mixed with fillers, making the imaging practically impossible with conventional optical methods. The detection of the presence and growth of electrical trees in opaque samples is therefore commonly only through PD measurements [6]. Special imaging techniques and sample preparation methods have been used when analysing the shape or structure of trees in filled epoxy

\footnotetext{
${ }^{1}$ R. S. is also with Universidad Tecnica Federico Santa Maria, Valparaiso, Chile
}

compounds. For imaging micro-filled epoxy, the authors in [3] used the 'leaf-like' sample configuration, which had only $200 \mu \mathrm{m}$ thickness. Visible light could penetrate such a thin sample and thus, trees were observed using optical microscopy. Others have sliced the sample near the needle tip and optically imaged the treeing area [7]. A different situation is encountered when imaging electrical trees in nano-filled materials. The filler concentration in nanocomposites $(\sim 1-5 \mathrm{wt} \%)$ is considerably lower than in micro-composites and the material is translucent enough for basic optical microscopy [6]. Localised images of individual tree branches in nanocomposites are commonly obtained using SEM for either a cross-section of the tree (tree holes) [6] or along the tree branches [4].

Recently, the authors have deployed X-ray computed tomography (XCT) and serial-block-face scanning electron microscopy (SBFSEM) techniques for 3D imaging of electrical trees in unfilled polymers $[5,8]$. In the past, 3D images of electrical trees in translucent XLPE have been generated using computed tomography and serial-sectioning methods combined with optical microscopy [9]. However, XCT and SBFSEM techniques have the capability of inspecting the internal structure of optically-opaque materials too. Moreover, 3D models (virtual replicas) are created and tree characteristics quantified [10]. In this paper, the first use of XCT and SBFSEM for 3D imaging electrical trees in micro and nanofilled epoxy is reported.

\section{METHODOLOGY}

To evaluate the capabilities of the $3 \mathrm{D}$ imaging techniques and compare electrical trees in unfilled epoxies with trees in filled epoxies; we present one unfilled epoxy sample, two micro-filled (5 and $20 \mathrm{wt} \%$ ) samples and one nano-filled (3 wt \%) epoxy sample, summarised in Table 1.

Samples were prepared using the conventional needle-toplane configuration with a gap of $\sim 2 \mathrm{~mm}$ between the needle tip and the bottom of the sample. Needles were supplied by Ogura and had $1 \mu \mathrm{m}$ tip radius. For the unfilled epoxy sample, the Huntsman Araldite® LY5052 - Aradur® HY5052 cold curing epoxy system was used. However, for filled epoxy samples, a hot curing epoxy system was chosen to facilitate the mixing: the Huntsman Araldite ${ }^{\circledR}$ CY225 - Aradur ${ }^{\circledR}$ HY925, which was mixed with either micro or nano silica $\left(\mathrm{SiO}_{2}\right)$. Micro-fillers had particles particle sizes 0.5-10 $\mu \mathrm{m}$ (approx. $80 \%$ between $1-5 \mu \mathrm{m}$ according to the data sheet), and nanofillers had specified particle size of $7 \mathrm{~nm}$.

To mix the epoxy with fillers and obtain an acceptable dispersion, a high-shear mixer (IKA T25 digital Ultra-Turrax® 
with the S25N-18G dispersing element) was used. The compound was mixed for $30 \mathrm{~min}$ at $\sim 6000 \mathrm{rpm}$ at $60^{\circ} \mathrm{C}$, which was found to be an adequate temperature that allowed the viscosity to be kept to reasonably low levels, and at the same time preventing the acceleration of the curing process. Then the compound was degassed in a vacuum oven at $\sim 60{ }^{\circ} \mathrm{C}$ for around $1 \mathrm{~h}$ to remove any gas / bubbles arising from the mixing process, and finally poured into the moulds ready for the curing cycle.

Electrical trees were grown by applying HV and monitored by PD measurements. Details of the samples and electrical stress are given in Table 1. Imaging trials using laboratory XCT had shown that micro-fillers are highly absorbent features, making the highly intense and coherent beam of a synchrotron necessary. Thus, all the samples were imaged firstly using XCT at I13i beamline at the Diamond Light Source synchrotron. Preparing for imaging, the samples were machined to create a 2-3 mm diameter cylinder of polymer containing the tree to be imaged. Each sample was scanned over a period of $\sim 2 \mathrm{~h}$ in which 1800 radiographs were taken with $3 \mathrm{~s}$ of exposure time per radiograph, using an X-ray energy of 11-13 keV. The pixel size was $0.45 \mu \mathrm{m}$ which provided a field of view of $1.8 \mathrm{~mm} \times 1.2 \mathrm{~mm}$ per radiograph [8]. Reconstructed images were cropped maintaining the region of interest where the tree was located.

After XCT, which is a non-destructive technique, Samples 3 and 4 were finally imaged using SBFSEM. The equipment used was a Gatan 3View ${ }^{\circledR}$ system housed within an FEI Quanta FEG 250 instrument. Samples were machined further to create a cube, containing the feature, with edges less than $1 \mathrm{~mm}$ and the needle was removed to prevent damage to the microtome knife. For the scan, the accelerating voltage was set to $3.5 \mathrm{kV}$ and the pressure chamber to $50 \mathrm{~Pa}$. The lateral pixel size was $\sim 0.1 \mu \mathrm{m}$ and the slice thickness $0.2 \mu \mathrm{m}$. For Sample 3, 2000 slices were taken with an image dimension of $4000 \times 4000$ pixels; for Sample 4, 3000 slices of $3052 \times 3052$ pixels were taken. In both cases, then the region of interest containing the feature was selected for 3D model generation. Virtual replicas of electrical trees were generated, segmenting the tree from the stack of images resulting from the XCT and SBFSEM scans [8], using Avizo imaging processing software.

\section{RESULTS}

In this section imaging slices and $3 \mathrm{D}$ renderings of the samples using XCT and SBFSEM are presented. These and other animations are available on You Tube [11].

\section{A. Sample 1: Unfilled epoxy sample}

A selected reconstructed slice and the 3D virtual replica generated for Sample 1 is shown in Fig. 1. The 3D model

\begin{tabular}{c|cc|cc|c} 
& \multicolumn{6}{c}{ Table 1. Experimental details of the samples. } \\
& \multicolumn{2}{|c|}{ Preparation } & \multicolumn{2}{c}{ Electrical stress } & \\
Sample & Filler & Conc. & Voltage & Duration & Imaging techn. \\
\hline 1 & Unfilled & - & $10 \mathrm{kV}$ & $1 \mathrm{~h} 50 \mathrm{~min}$ & XCT \\
\hline 2 & Micro-silica & $5 \mathrm{wt} \%$ & $8-10 \mathrm{kV}$ & $45 \mathrm{~min}$ & XCT \\
\hline 3 & Micro-silica & $20 \mathrm{wt} \%$ & $9-12 \mathrm{kV}$ & $2 \mathrm{~h} 20 \mathrm{~min}$ & XCT \& SBFSEM \\
\hline 4 & Nano-silica & $3 \mathrm{wt} \%$ & $8-10 \mathrm{kV}$ & $1 \mathrm{~h} 10 \mathrm{~min}$ & XCT \& SBFSEM \\
\hline
\end{tabular}

XCT: micro-XCT beamline I13 at Diamond Light Source synchrotron. Voxel size XCT: $0.45 \mu \mathrm{m}$. SBFSEM available at the University of Manchester.

Lateral pixel size: $\sim 0.1 \mu \mathrm{m}$, slice thickness: $0.2 \mu \mathrm{m}$.

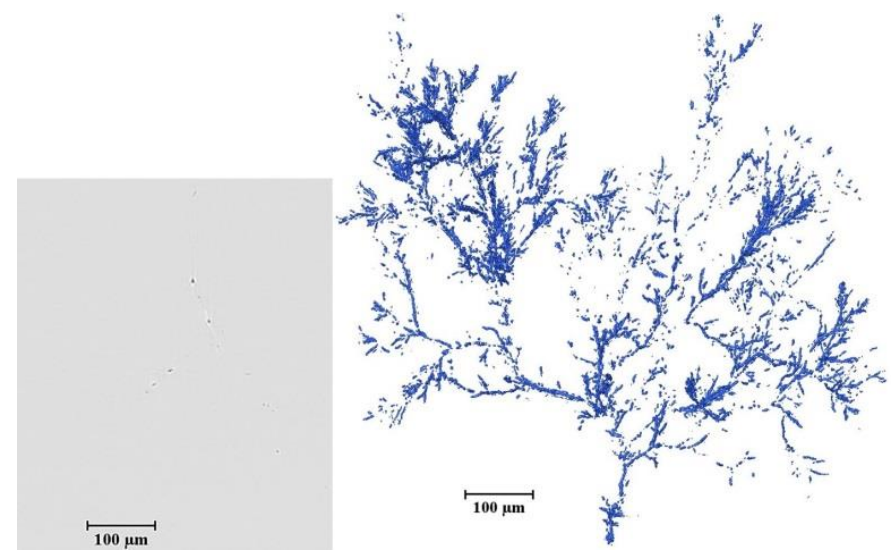

Fig. 1. Reconstructed slice and 3D rendering for Sample 1, using XCT.

(Fig. 1 - right) was generated using 1780 reconstructed slices, equivalent to $800 \mu \mathrm{m}$ of tree length. With this model, some characteristics of the tree were calculated. The mean diameter of the tree channels was $3.0 \mu \mathrm{m}$ with a standard deviation of $31 \%$ and the tree volume and surface area were $2.3 \times 10^{5} \mu \mathrm{m}^{3}$ and $3.6 \times 10^{5} \mu \mathrm{m}^{2}$ respectively, resulting in a surface/volume ratio equal to 1.6. The convex hull volume was calculated to be $2.3 \times 10^{8} \mu \mathrm{m}^{3}$ and thus, the proportion of volume degraded was $0.1 \%$.

\section{B. Sample 2 and 3: Micro-filled epoxy samples}

A selected reconstructed slice and the 3D virtual replica for each of Samples 2 and 3 are shown in Fig. 2 and 3 respectively. For Sample 2 it was possible to segment parts of the electrical tree (Fig. 2 - right) from the reconstructed slices (Fig. 2 - left); however, the entirety of the tree was not revealed, only the general structure is revealed. On the other hand, for Sample 3, the contrast between tree channels and the background obtained
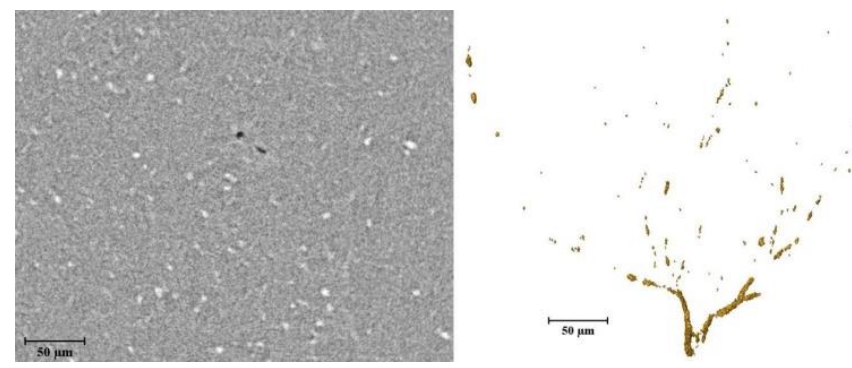

Fig. 2. Reconstructed slice and 3D rendering for Sample 2, using XCT.
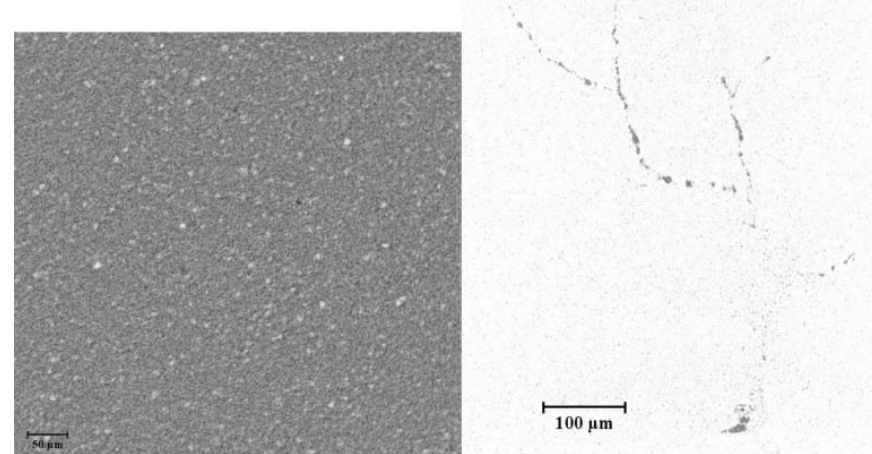

Fig. 3. Reconstructed slice and 3D rendering for Sample 3, using XCT. 
using XCT was not high enough to successfully segment the tree. Alternatively, for visualisation of the general tree structure, a 3D rendering of the tree was obtained using the original grey-level slices, which is shown in Fig. 3-right. Although the generation of the virtual replica was not possible in this case, the presence and structure of an electrical tree was identified.

Sample 3 was additionally imaged using SBFSEM, which is represented in Fig. 4. From the slice shown on the left, it can be seen that the dispersion of micro-fillers is good. The generation of this 3D model was difficult, since the slicing procedure created artefacts. Micro silica fillers are much harder that the host epoxy, and when the knife encountered a filler particle, the filler could have pushed the epoxy or been dragged with the knife movement, creating cavities surrounding the fillers. Consequently, for the model shown in Fig. 4-right, semimanual segmentation was required. One advantage of having the $3 \mathrm{D}$ dataset is that the sample can be virtually sliced in any direction. 'Slicing' in a plane parallel to the direction of the needle tends to cut through the branches longitudinally, and features, such as a bifurcation when the tree encounters a filler particle, can be observed (red circle, Fig. 5 - right).

To calculate the mean diameter of tree channels, a subvolume of the tree shown in Fig. 4-right was segmented, because it was uncertain that the model generated was composed only of tree channels and not also of cavities created during the slicing. Using the sub-volume model (shown in Fig. 5-left), the mean diameter of the tree channels was found to be $0.6 \mu \mathrm{m}$ with a standard deviation of $31 \%$, which is

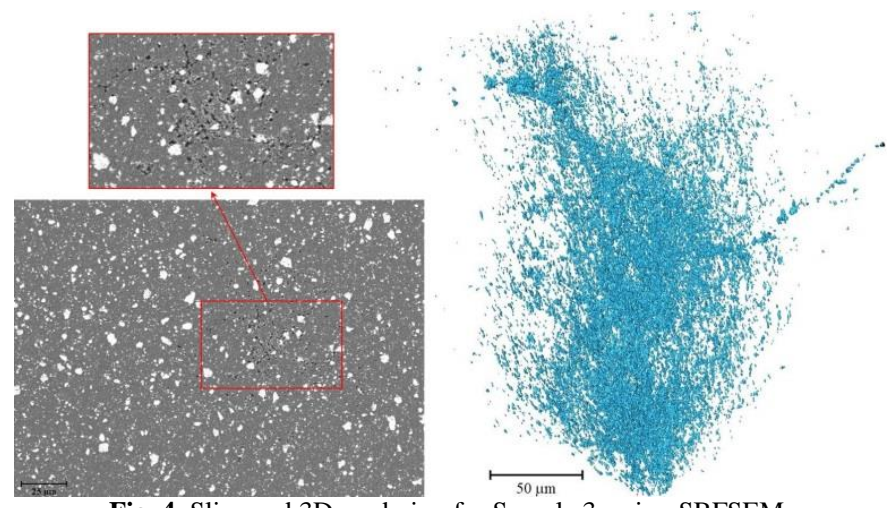

Fig. 4. Slice and 3D rendering for Sample 3, using SBFSEM.

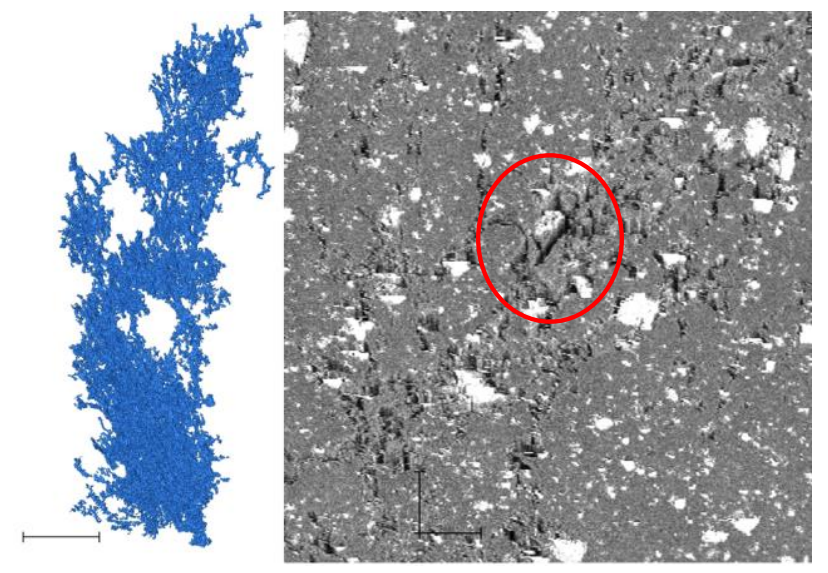

Fig. 5. 3D rendering of sub-volume Sample 3 and virtual slice in the needle plane direction, using SBFSEM. Scale bar left: $20 \mu \mathrm{m}$, right: $10 \mu \mathrm{m}$.

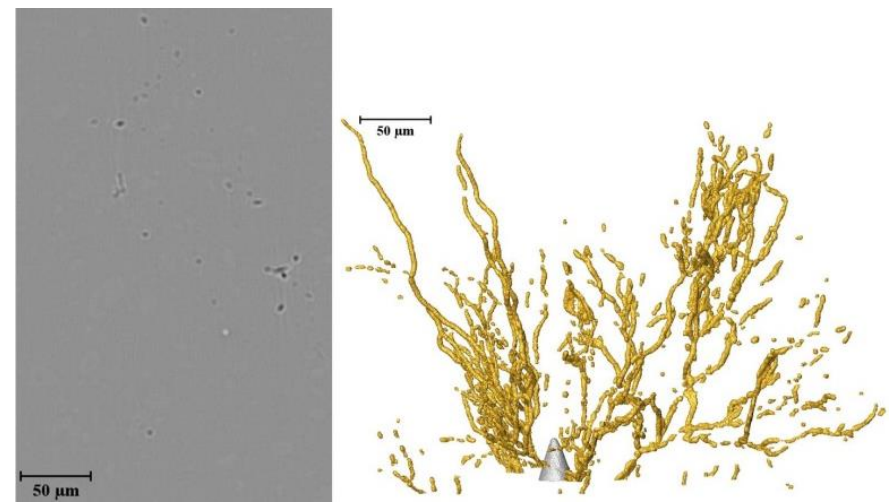

Fig. 6. Reconstructed slice and 3D rendering for Sample 4, using XCT.

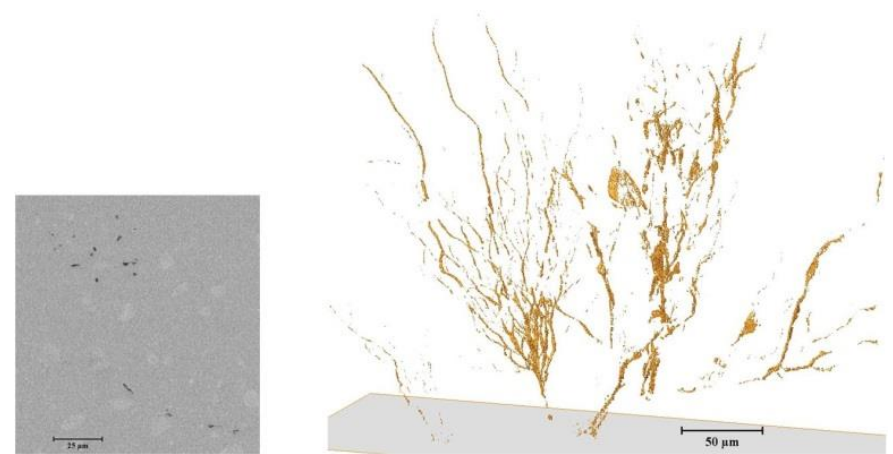

Fig. 7. Slice and 3D rendering for Sample 4, using SBFSEM.

smaller than the diameter reported previously for unfilled epoxy using SBFSEM, which was in the range 1-2 $\mu \mathrm{m}$ [8].

\section{Sample 4: Nano-filled epoxy sample}

Sample 4 was imaged using synchrotron-based micro-XCT first, see Fig. 6. The imaging situation is similar than with unfilled epoxy samples (see Sample 1 and [5]), electrical tree channels are clearly distinguished in the slices (Fig. 6 - left). For Sample 4, it is seen that trees started below the needle tip.

The 3D model (Fig. 6 - right) was generated considering 593 reconstructed slices, equivalent to $267 \mu \mathrm{m}$. The mean diameter of the tree channels was calculated to be $3.2 \mu \mathrm{m}$ with a standard deviation of $18 \%$ and the tree volume and surface were $7.3 \times 10^{4} \mu \mathrm{m}^{3}$ and $9.7 \times 10^{4} \mu \mathrm{m}^{2}$ respectively, resulting in a surface/volume ratio equal to 1.3 . The convex hull volume was calculated to be $1.5 \times 10^{7} \mu^{3}$ and thus, the proportion of volume degraded was $0.5 \%$. Branch diameters are similar to the obtained for Sample 1unfilled epoxy $(3 \mu \mathrm{m})$.

Additionally, the imaging results for Sample 4 using SBFSEM are shown in Fig. 6. The model generated presented many disconnected branches, therefore, its characteristics have not been quantified as these would be error prone.

\section{DISCUSSION}

The Synchrotron XCT system could not revealed the entire structure of the electrical trees in micro-filled epoxy. Tree channels were not well resolved due to the poor contrast between the tree channels and the filled-epoxy. For Sample 3 (20\% micro), the generation of a 3D model was not possible. The contrast-noise ratio of the data could however, be improved by longer exposure and hence longer scan times.

As expected, more details were obtained using SBFSEM. Not only were the fillers clearly identified, but so were the 
electrical tree channels at finer resolution. The basic replica obtained for Sample 3 using XCT suggested that the tree was a branch-type structure with few branches (Fig. 3); however, SBFSEM revealed that the tree was more bush-type with many fine branches instead (Fig. 4). Moreover, by virtual slicing, bifurcation of branches encountering a filler particle was observed (Fig. 5-right). However, the slicing procedure of SBFSEM in Sample 3 created artefacts (artificial features imposed in the imaging procedure) around some filler particles. Due to the difference in hardness between filler particles and the host epoxy, during slicing the knife pushed the filler particles against the host epoxy and created interstitial space surrounding the filler. As a result, it remains uncertain how the interaction of a tree branch and a filler particle is in the $<2 \mu \mathrm{m}$ range.

On the other hand, imaging electrical trees in nano-filled epoxy is less challenging than in micro-filled epoxy, and similar to the case of unfilled epoxy. The mean diameter of tree channels in Sample 4 (nano-filled) was $3.2 \mu \mathrm{m}$, which is similar to the diameter in Sample 1 - unfilled epoxy $(3.0 \mu \mathrm{m})$. However, the mean diameter of tree channels in the selected sub-volume of micro-filled Sample 3 (Fig. 5-left) was $0.6 \mu \mathrm{m}$, which is considerable smaller than the $\sim 3 \mu \mathrm{m}$ obtained for the nano-filled and unfilled epoxy cases. This result suggests that trees in micro-filled epoxy grow having more branching and consequently, smaller mean diameter of tree channel. Previously it has been suggested that more branching is expected in trees in filled compared to unfilled epoxies (e.g. [3]). Here we have identified smaller diameters, perhaps as a consequence of increased branching. More work is required to confirm this is a generic rather than material-specific result. This smaller diameter of tree branches in micro-filled samples should be the main reason why the micro-XCT synchrotron system, with a resolution $\sim 1 \mu \mathrm{m}$ was not capable of revealing most of the tree.

Virtual replicas obtained using both XCT and SBFSEM techniques have disconnected branches (e.g. Fig 1, 6 and 7). The reason for that is not clear, but it could be related to a section of smaller diameter or even a different nature of branch in that section that yields poor contrast areas. This situation prevented further quantification of tree characteristics.

\section{CONCLUSIONS}

The capabilities of XCT and SBFSEM techniques for 3D imaging electrical trees in filled epoxy composites have been evaluated in this paper. Fillers were either micro (5 and $20 \mathrm{wt} \%$ ) or nano (3wt\%) scale sizes of silica powder.

Overall, XCT and SBFSEM are able to image electrical trees in filled epoxy resin. However, imaging in micro-filled epoxy was considerable more challenging than in nano-filled epoxy, the latter being a similar imaging situation to unfilled epoxy. Using XCT, only the general structure of the tree in microfilled epoxy could be revealed but much detail was lost compared to SBFSEM. Micro-silica fillers are X-ray absorbing features, and therefore, one of the limitations for XCT is the amount of fillers in the sample. Trees were observed in microfilled epoxy up to $20 \mathrm{wt} \%$, but could not be quantified.

Using SBFSEM for imaging of micro-filled samples, created artefacts due to the slicing procedure and the difference in hardness between filler particles and the host epoxy.
Nevertheless, the technique allowed the observation of the tree interaction with fillers by virtually slicing of the 3D dataset. In addition, the mean tree diameter was calculated to be $0.6 \mu \mathrm{m}$ in a sub-volume of the tree in the $20 \mathrm{wt} \%$ micro-filled sample. This value is considerably smaller than the diameters obtained for unfilled and nano-filled epoxy samples, both around $3 \mu \mathrm{m}$. This smaller size may be the reason why micro-XCT imaging could not revealed the entirety of tree in micro-filled samples.

For nano-filled epoxy, the imaging situation is closer to the unfilled epoxy case. Trees could be revealed using either XCT or SBFSEM, however, it is impossible to capture the entire structure of the tree with sufficient resolution to analyse the interaction tree-filler particle at the same time.

Overall, imaging electrical trees in filled-epoxies remains a challenging task. Currently, none of the techniques trialled provided an ideal solution for imaging electrical trees in microfilled epoxy.

\section{ACKNOWLEDGMENT}

The authors thank Christoph Rau, Joan Vila-Comamala and Andrew Bodey at I13 beamline Diamond Light Source synchrotron for their assistance. Roger Schurch would like to acknowledge the scholarship support of CONICYT (Chilean Research Council in Science and Technology). Philip Withers would like to acknowledge funding from EPSRC for the Manchester X-ray Imaging Facility under EP/F007906/1 and EP/F028431/1.

\section{REFERENCES}

[1] T. Tanaka, "Dielectric nanocomposites with insulating properties", IEEE Trans. Dielectr. Electr. Insul., Vol. 12, pp. 914-928, 2005

[2] T. Tanaka, Y. Ohki, M. Ochi, M. Harada, and T. Imai, "Enhanced partial discharge resistance of epoxy/clay nanocomposite prepared by newly developed organic modification and solubilization methods", IEEE Trans. Dielectr. Electr. Insul., Vol. 15, pp. 81-89, 2008.

[3] R. Kurnianto, Y. Murakami, M. Nagao, and N. Hozumi, "Investigation of filler effect on treeing phenomenon in epoxy resin under ac voltage", IEEE Trans. Dielectr. Electr. Insul., Vol. 15, pp. 1112-1119, 2008.

[4] M. Danikas and T. Tanaka, "Nanocomposites-a review of electrical treeing and breakdown", IEEE Electr. Insul. Mag. Vol. 25, pp. 19-25, 2009.

[5] R. Schurch, S. M. Rowland, R. S. Bradley, and P. J. Withers, "Imaging and analysis techniques for electrical trees using $\mathrm{X}$-ray computed tomography”, IEEE Trans. Dielectr. Electr. Insul., Vol. 21, pp. 53-63, 2014.

[6] C. Yu, T. Imai, Y. Ohki, and T. Tanaka, "Tree initiation phenomena in nanostructured epoxy composites", IEEE Trans. Dielectr. Electr. Insul., Vol. 17, pp. 1509-1515, 2010

[7] T. Imai, F. Sawa, T. Nakano, T. Ozaki, T. Shimizu, M. Kozako, et al., "Effects of nano- and micro-filler mixture on electrical insulation properties of epoxy based composites", IEEE Trans. Dielectr. Electr. Insul., Vol. 13, pp. 319-325, 2006.

[8] R. Schurch, S. M. Rowland, R. S. Bradley, and P. J. Withers, "Comparison and Combination of Imaging Techniques for Three Dimensional Analysis of Electrical Trees", Submitted to IEEE Trans. Dielectr. Electr. Insul., 2014.

[9] H. Uehara and K. Kudo, "Three-Dimensional Fractal Analysis of Real Electrical Trees in Polyethylene", Jap. J. App. Phys., Vol. 38, pp. 36043610, 1999

[10] R. Schurch, S. M. Rowland, R. S. Bradley, and P. J. Withers, "Three dimensional characterisation of electrical trees", IEEE Conf. Electr. Insul. Dielectr. Phenomena (CEIDP), pp. 494-497, 2013.

[11] R. Schurch, S. M. Rowland, R. S. Bradley, and P. J. Withers. (2013, 11th June). Electrical Trees CEIDP. Available: http://www.youtube.com/user/ElectricalTreesCEIDP/video 